trepreneurialism as a justifiable response.)

(2) An on-campus tourism enterprise should be viewed as entirely functional in terms of using the resource base of the institution in order to maximize revenue, and in the words of one informant: 'to support its mainstream educational activities'. This argument is based on the premise that it is acceptable to operate a business within a university setting as long as the profits from that business are ploughed back into the overall structure which supports it, ie the university.

(3) A non-educationally based enterprise operating within an educational establishment is bound to rouse debate due to the nature of its very existence. Some commentators may argue that any business operating within a university setting should reflect its position. In other words, if holidays are to be offered as a means of generating revenue, then these holidays should have an educational element. It is difficult to suggest at the present time which tourism markets will be significant in the future. It is quite feasible that educational and special-interest tourism will experience further growth, particularly in relation to short breaks. This would provide universities with an opportunity to develop as specialist tourism providers at suitable times of the academic year.

In the study, opinion was mixed on the issue of appropriateness. Some felt that institutions 'should go where the market is' if the main factor is raising funds. Others were opposed to noneducational campus holidays and argued for a stronger element of liaison between academics and holiday organizers in terms of developing packages.

This discussion raises some debate about the conflict of interests in a multi-goal organization - in this case, a higher education establishment. Overall, organizational stakeholders are supportive (or at least understanding) of the entrepreneurial role being taken by university administrators but do express some concerns. With regard to the use of campus facilities for tourism, this is seen as a sensible use in terms of utilizing otherwise idle resources, providing useful additional income and a good quality tourism service to customers. However, sensitive management at the site level is required to minimize any conflicts arising.

The initial indications of this study show that there are some potentially wide-ranging policy implications relating to the development of campusbased tourism, notably the strong element of planning and management required to balance the needs of all the stakeholders in a multiple-goal organization. It is likely that this tourism sector will see further growth, which gives impetus for further study. Research is now needed to establish the national picture of campus-based tourism, with an emphasis on its significance as a sector in the UK tourism market, to provide a statistical basis. The perceptions of non-users and experience of stakeholders to help inform product and marketing strategy as well as to minimize conflict needs further attention. Additional research could be undertaken on the role of the university as a provider of alternative forms of tourism, particularly in terms of social tourism.

Jo Connell

Department of Land Use and Rural Management

Seale Hayne Faculty

University of Plymouth

Newton Abbot

Devon TQ12 6NQ, UK

\section{References}

'Murphy, P Tourism. A Community Approach Routledge, London (1985)

${ }^{2}$ Lockwood, G and Davies, J L 'University organisation \& management' Int $J$ Institutional Management in Higher Education 19855 (3) $183-190$

${ }^{3}$ Walford, G Restructuring Universities: Politics and Power in the Management of Change Croom Helm, Beckenham (1987) ${ }^{4}$ Hall, C M and Weiler, B Special Interest Tourism Belhaven Press, London (1992)

${ }^{5}$ Connell, $J$ 'An investigation into campusbased tourism' unpublished MA thesis, University of Exeter, 1995

'Shock, M Report of the Steering Committee for Efficiency Studies in Universities Committee of Vice Chancellors \& Princip als (1985)

\title{
Cross-cultural differences in the practices of hotel managers: a study of Dutch and Belgian hotel managers
}

In the service sector there has been debate and research on whether it is the culture of the organization or that of the location that shapes hotel management practice - particularly given the internationalization of certain, mostly US-style practices. Here Myriam Jansen-Verbeke and Liesbet Steel of Rotterdam's Erasmus University report on a survey of hotel managers in Belgium and The Netherlands. Differences are slight, but whether this is because of a shared cultural background or a homogenizing organizational culture is not clear. Comparisons with a larger study of managers in 13 countries worldwide are made. Copyright (C) 1996 Elsevier Science Ltd

The service sector has been characterized in the last decade by enormous growth. This growth was accompanied by expansion to different parts of the world. The service sector is internationalizing. US companies in particular are located all over the world. Examples of this expansion are the
McDonald's restaurants, international hotel chains and the success of other franchise companies.'

In the literature this phenomenon of internationalization is often associated with the term 'globalization'. The process of globalization is based on the convergence of consumer preferences. 
as a result of the technological evolution and economics of scale in the enterprise. However, there is much controversy in the literature over whether consumer preferences are really converging or rather diverging.

Moreover, the globalization of consumer preferences does not necessarily imply convergence in management practices. To what extent do differences in management disappear (convergence) or remain present (divergence)? Total convergence or divergence of business functions and procedures are two extremes. Often companies find themselves on the continuum between those two extremes. Business functions (R\&D, finance, production, administration and marketing) can be organized in a more standardized or a rather tailored way. ${ }^{2}$ The term globalization involves different components: business functions (investments, production, sales, etc), competition, consolidation of resources, human resources and technological aspects. ${ }^{3}$

Levitt ${ }^{4}$ can be considered an important advocate of the convergence hypothesis. He claims that certain organizational structures are universal and superior in current technological society. All organizations are converging towards this ideal. In addition, consumer preferences are becoming homogeneous, which gives rise to a standardization of products and services. These standard products and services have a high quality and a low price.

Other authors assert that organizations are culture-bound. Consequently, cultural characteristics in different parts of the world lead to divergence rather than convergence in management and organizations. Adler, Dokter and Redding conclude based on their review of the management literature that many forms of management can be effective. The most effective form is determined by the culture of the society in question along with other aspects.

International hotel companies seem to have a uniform and heavily standardized approach in different countries of the world, ${ }^{6,7}$ though research has shown that this process of globalization does not necessarily overrule cultural identity. Pizam ${ }^{8}$ analysed the management practices of international hotel companies. The cultural dimensions used in his research were derived from the cross-cultural study of Hofstede."

In order to increase the validity of the research other countries were added to the initial sample. The sample was elaborated with hotels in Belgium and The Netherlands. The study examined the differences and commonalities in hotel management practices, which were linked to the differences in national culture.

\section{Cultural dimensions of Hofstede}

In his survey Hofstede examined cultural differences in management values of employees in the multinittional firm IBM. In this study an extensive database $(116000$ questionnaires) was used. Questionnaires were distributed among the employees of the multinational in several countries. In the questionnaire the employees were asked for their work values."

Hofstede distinguished four cultural dimensions on the basis of the differences in work values across the countries involved in the survey: power distance, uncertainty avoidance, individualism-collectivism, masculinitvfemininity.

Power distance can be defined as the extent to which the less powerful members of the organization within a country expect and accept that power is distributed unequally. "The dimension gives an indication of independence. In countries with a small power distance, there is a limited dependence of subordinates on bosses. In large power distance countries, however, the dependence of the subordinates on their bosses is rather large.

Uncertainty avoidance is determined by the extent to which the members of a given culture feel threatened by uncertain and unknown situations. In countries with high uncertainty avoidance, companies have a lot of formal regulations and procedures $\left({ }^{10} \mathrm{p} 113\right)$.

The individualism dimension refers to societies where ties between indi- viduals are loose: everyone is expected to look after him- or herself and his or her family. In collectivist countries, however, people are integrated from birth onwards in strong social groups. These groups serve as protection throughout people's lifetimes ( ${ }^{10}$ p 51$)$.

Finally, the masculinity dimension points to societies where there exists a clear distinction between the social roles of men and women, whereas in feminine cultures the role distinction is less clear ( ${ }^{10}$ pp 81-82).

On the basis of these four dimensions Hofstede distinguished a limited set of homogenous clusters. Countries belonging to the same cluster showed similar scores on the different dimensions. Furthermore he studied the relationship between the national culture (scores on the dimensions) and some specific management issues. In this way he illustrated the effect of a country's cultural identity on important management practices such as organization structure, leadership and motivation.

Hofstede's method has been reviewed by several authors in the management literature. " $1 \leqslant$ An important point of critique is that the use of dimensions leads to an oversimplification and generalization. Moreover it leads to stereotyping. Adler ${ }^{14}$ also questioned the fact that culture was equated with nation-state. In this way cultural differences within nations are not taken into account.

However, these critics do not imply that Hofstede's study was useless. The theory can be considered as a good framework for cross-cultural research. ${ }^{15}$ The cultural dimensions of Hofstede have been used in several other cross-cultural studies.

\section{Hotel management in Belgium and The Netherlands}

The purpose of the research in Belgium and The Netherlands was to examine whether the two countries can be considered as one cultural area in relation to hotel management.

The sample includes two international hotel companies - Hilton International and Holiday Inn - in the two countries. In a written questionnaire 
Table 1 Cultural dimensions for Belgium and The Netherlands

\begin{tabular}{lcc}
\hline Index & Belgium & Netherlands \\
\hline Individualism-collectivism & 40.27 & 42.2 \\
Power distance & 13.06 & 13.66 \\
Uncertainty avoidance & 26.23 & 26.03 \\
Masculinity-feminity: & & 564.74 \\
male & 548.94 & 9.96 \\
macho-ism & 11.46 & \\
\hline
\end{tabular}

managers were asked about their everyday practices in hotel management. Owing to the homogenous sample (multinational hotel company, 4/5 stars) other variables such as organization culture could be held constant. In this way differences in the practices of hotel managers could be attributed only to the differences in national culture. However, the homogenous sample also implied that only differences (and not similarities) could be attributed to national culture. Hence the common practices could be the result of a common national culture or of a common organizational culture. As will be shown, organizational culture has a strong influence on the behaviour of the employees, especially in the hospitality sector.

Differences in the practices of hotel managers in Beigium and The Netherlands were examined with 45 questions, which were used to calculate the appropriate indices. Every index could be associated with a dimension described in the work of Hofstede. The masculinity/femininity index was divided into two separate indices. The male index points to the extent to which roles in society are stereotyped. The second index is called the macho index.

The sample consisted of 64 respondents. Managers of different nationalities (Dutch, Belgian, French and German) were included. In the research only differences between Belgian and Dutch hotel managers were investigated. As a consequence other nationalities were left out of the sample. Also, a lot of Belgian hotels were managed by Dutch persons. These managers are influenced by both the Dutch and Belgian cultural environment. For this reason they were not included with the other results/data in the sample.
It should be noted that Hofstede emphasized the work values of the respondents, whereas Pizam asked for their management practices. Hofstede assumed that differences between nationalities are reflected in values rather than in practices. ${ }^{10}$ Pizam made a distinction between organization structure and behaviour in organizations. While national culture hardly affects the structure of the organization, it influences the behaviour of people in the organization. ${ }^{8}$ Hence, cultural differences were measured based on the management practices.

The index values are presented in Table 1. A small value for the individualism/collectivism dimension points to an individual culture, while a large value indicates a collectivist culture. A small score on the power distance index indicates a large power distance and vice versa. The same can be said for the uncertainty avoidance. A large score on the macho index signifies a large macho-ism. A large score on the male index indicates a strong masculine culture, whereas a low value can be associated with a feminine culture.

At first sight, the figures in Table 1 only show small differences between the two countries. The largest deviation can be found in the individualism-collectivism index and the masculinity-femininity index. In order to gain more insight into the real differences the indices were analysed in their component parts.

The extent to which managers are interested in the private life and the well-being of their employees gives an indication of the degree of individualism. Belgian managers attend fewer family gatherings of their employees than Dutch managers. The individualism-collectivism index also refers to the degree of confidence managers have in their subordinates. Dutch managers show a greater degree of trust than their Belgian colleagues.

The degree of openness, the directness of hotel managers in relation to their subordinates, methods used to solve conflicts and number of times that managers defend their subordinates against criticism can be identified as additional aspects of the individualism-collectivism index. The Belgian and Dutch management approach does not differ on these aspects. Both can be considered strong individualistic cultures.

The power distance score reflects the frequency with which the manager consults employees before taking a decision, the visibility of status symbols, etc. There were no significant differences found in these characteristics.

The survey also investigated the use of social codes by hotel personnel, control of application of the company procedures manual and uniformity in addressing the guests. These procedures indicate the extent to which hotel management is regulated in both countries. This is seen as an indicator of the amount of uncertainty avoidance. There was no significant difference found between the countries.

Other elements of the uncertainty index refer to the number of decisions that are taken democratically, the extent to which events are planned and tolerance of unusual behaviour of personnel. Again no differences were found between the Belgian and Dutch hotel managers.

The male index is calculated based on the percentages of men and women who are expected to hold particular positions. The index reflects stereotyping in social patterns and gives an indication of the masculinity in society.

Dutch as well as Belgian results suggest that the hotel industry is very masculine. Some functions such as front office manager, personnel manager and executive housekeeper are considered to be female tasks. These functions involve intensive human interactions. Other functions, such as general manager and food and beverage manager, are mainly designed for 
men. These results indicate a strict separation of social roles in both countries.

The index of macho-ism indicates the amount of meetings managers have with their colleagues. Belgian managers seem to meet their colleagues less frequently than do the Dutch. The index also refers to the way the salary or financial reward of a subordinate is determined and the extent to which managers favour stronger or more sensitive subordinates. On the basis of the results of the survey no differences were found in those two characteristics between the two countries.

\section{Interpretation and comparison of the results}

The analysis shows that there are only a few differences in the practices of hotel managers in Belgium and The Netherlands. This could be explained by the fact that Belgium and The Netherlands belong to one and the same cultural region. Another explanation could be found in the homogenizing influence of organizational culture in hotel companies or the culture of the hotel industry in general.

Most multinational companies have a strong organization culture. This is reflected in the amount of uniform procedures and practices. In this way the culture of the organization could have a homogenizing effect on the national culture. All Hilton managers in Belgium and The Netherlands, for example, gave the same answer to the question related to the feedback procedure. All managers use a formal written and oral feedback procedure. In this way the organizational culture of Hilton seems to overrule the national culture.

The similarities between Belgium and The Netherlands can also be explained by the homogenizing culture of the hotel industry itself. The hotel industry has a unique culture in which it distinguishes itself from other industries. We could question whether hotel managers act in the same way because the culture in the hotel industry requires this way of behaviour. The hotel sector is characterized by uniform procedures in contacts with the guests, emphasis on quality of service and sense of security in service supply. ${ }^{7}$

The tourist industry, and especially the hotel industry, shows a strong internationalization process. This internationalization is accompanied by an increasing standardization of products and procedures (management style). Both trends are intertwined. The standardization is strengthened by strategic alliances - such as franchising - in a lot of hotel chains, where strong control is exercised over buildings, material and procedures. ${ }^{16}$ Individual franchises obtain many advantages with the franchise contract, such as a well-known brand name, central reservation system, marketing support and staff training.

The franchise system is applied on an international scale in the hotel sector. Several American brand names now receive international fame through the system (eg KFC, McDonald's, Hilton). However, the franchise system has not been limited to the American continent. Other brands have now been introduced to the US market from other countries and continents with a similar system (eg Sbarro, Accor). ${ }^{7}$

The uniform approach can be considered an ideal marketing tool. International hotel companies can guarantee a certain level of service quality. Customers can be confident that they will find the same level of service quality all over the world. For many hotel chains the homogeneity between their affiliated hotels is considered an essential element for achieving overall guest satisfaction and repeat business. Branding elements such as hotel name, symbol, slogan and design are supported to make the service products easily recognizable to the travelling public."

From the previous discussion it is clear that management practices in Belgium and The Netherlands seem to converge rather than diverge. But to examine the process more precisely a more detailed longitudinal study is required. It should also be mentioned that the study deals with management practices rather than the values held by the managers. Authors such as
Hofstede and Laurent claimed that a strong organizational culture could lead to a convergence in practices but not in values. Practices are only a reflection of deeper values. ${ }^{17.18}$

The homogenizing influence of the hotel organization and the hotel industry seem to be a reasonable explanation for the similarities in management practices. However, the question still remains whether those uniform rules and procedures can be applied in every nation or country without being limited by national culture.

To answer this question we can compare the results of the Belgium/ Netherlands survey with the results of similar research in other countries.

\section{Hotel management in other countries}

Pizam analysed the management practices in 13 other countries across the world: Australia, the United Kingdom, the United States, Ireland, Germany, Austria, France, Spain, Italy, Indonesia, Malaysia, Korea and Japan. The sample was mainly composed of the hotel chains Hilton International, Forte and Accor. In total 602 respondents filled out the questionnaire. In the sample both genders were present: $30 \%$ women and $70 \%$ men. The index values of the studies are presented in Table 2 .

The individualism-collectivism index shows that most of the countries can be placed on the continuum between individualism and collectivism. Belgium and The Netherlands are positioned between those two extremes. Only Spain can be considered a collectivist country. Pizam considered Spain. Korea. Italy and Japan as countries with a significant power distance. The other countries in the sample showed a moderate power distance. Belgium and The Netherlands also belong to this category. All countries showed great similarity in the way they avoided uncertainty in the hotel business. The analysis also showed that Italian and Belgian managers behave in a more macho manner than their colleagues in other countries. Other countries such as Japan, Korea and Malaysia are less macho in their behaviour." 
Table 2 Cultural dimensions in 13 other countries

\begin{tabular}{llllrl}
\hline Country & $\begin{array}{l}\text { Individualism/ } \\
\text { collectivism }\end{array}$ & Power distance & $\begin{array}{l}\text { Dimensions } \\
\text { Uncertainty } \\
\text { avoidance }\end{array}$ & Macho & Male \\
\hline Australia & 41.74 & 14.74 & 23.35 & 10.38 & 615.97 \\
UK & 40.36 & 13.24 & 22.74 & 10.35 & 558.32 \\
USA & 39.91 & 12.98 & 22.11 & 10.04 & 603.16 \\
Ireland & 40.41 & 12.70 & 23.21 & 9.64 & 558.81 \\
Germany & 41.32 & 13.33 & 20.68 & 9.91 & 581.67 \\
Austria & 41.13 & 13.72 & 21.35 & 10.01 & 596.96 \\
France & 39.79 & 14.34 & 22.05 & 9.09 & 563.03 \\
Spain & 51.02 & 10.11 & 21.46 & 10.60 & 619.00 \\
Italy & 41.98 & 11.80 & 23.15 & 11.55 & 681.15 \\
Indonesia & 44.29 & 13.65 & 20.23 & 8.73 & 650.09 \\
Malaysia & 45.22 & 14.40 & 21.85 & 10.00 & 607.45 \\
Korea & 46.20 & 11.28 & 23.19 & 8.00 & 658.63 \\
Japan & 42.74 & 12.63 & 21.97 & 9.28 & 647.41 \\
Belgium & 40.27 & 13.06 & 26.23 & 11.46 & 548.94 \\
Netherlands & 42.20 & 13.66 & 26.03 & 9.96 & 564.74 \\
\hline
\end{tabular}

Source: survey Belgium/Netherlands and Pizam ${ }^{8}$

\section{Conclusions}

The previous analysis suggests that national culture has a significant influence on the practices of hotel managers. The survey indicates several differences in practices across cultures Spain can be considered as a collectivist country, whereas Italy tends to be more 'macho'. Asian countries, however, show most differences on the cultural dimensions. There are considerable differences between the managers in East and West.

Moreover, it is not unlikely that real cultural differences between countries are even larger than the variance observed in the survey. This can be explained by the strong organizational culture within international hotel chains. Large international enterprises are characterized by uniform rules and procedures. As a consequence, international management practices show a certain homogenization. Cultural differences between Belgium and The Netherlands are probably larger than is reflected in the results of the survey but they are weakened when only the practices of hotel managers in both countries are studied. International

\section{References}

'Davidson, $\mathrm{W} \mathrm{H}$ 'The role of global scanning in business planning' Organizational Dynamics 199119 (3) 5-16

${ }^{2}$ Quelch, J A and Hoff, E J 'Customizing global marketing' Harvard Business Review 1986 (May-June) 59-68

${ }^{3}$ Clark, $\mathrm{J}$ and Arbel, A 'Producing global managers: the need for a new paradigm Cornell HRA Quarterly 1993 (August) 8389

${ }^{4}$ Levitt, $T$ 'The globalization of markets' Harvard Business Review 198383 (3) 92 102

${ }^{5}$ Adler, J N, Dokter, R and Redding, J G 'From the Atlantic to the Pacific century: cross-cultural management reviewed' $J$ Management 198612 (2) 295-318

${ }^{6}$ Fung, R J Organizational Strategies for Cross-cultural Cooperation Eburon, Delft (1995)

${ }^{7}$ Go, F and Pine, R Globalization Strategy in the Hotel Industry Routledge, London (1995)

${ }^{8}$ Pizam A Managing Cross-cultural Hospitality Enterprises working paper, Florida University (1993)

${ }^{4}$ Hofstede, G Culture's Consequences. In ternational Differences in Work-related Values Sage, London (1980)

${ }^{10}$ Hofstede, G Culture and Organizations: Software of the Mind McGraw-Hill, London (1991) 27

"Hunt, J W 'Applying American behavioural science: some cross-cultural problems' Organizational Dynamics 19819 (3) $55-62$

${ }^{12}$ Goodstein, LD 'American business values and cultural imperialism' Organizational Dynamics 19819 (3) 49-54

${ }^{13}$ Jaeger, A M Organizational development and national culture: where is the fit? Academy of Management Review 198611 (1)

${ }^{14}$ Adler, $\mathrm{N}$ 'Cross-cultural management: the ostrich and the trend Academy of Management Review 19838 (2) 226-232

${ }^{15}$ Hunt, J W Applying American behavioral science: some cross-cultural problems' Organizational Dynamics 198110 (2) 55-62

${ }^{16}$ Witt, S F and Moutinho, L Tourism Marketing and Management Handbook Prentice Hall, New York (1995)

${ }^{17}$ Hofstede, G, Neuijen, B, Ohayv, D D and Sanders, $G$ 'Measuring organizational cultures: a qualitative and quantitative study across twenty cases' Administrative Science Quarterly 199035 (2) 286-316

${ }^{18}$ Laurent, A 'The cultural diversity of Western conceptions of management' Int Studies of Management and Organisations 198313 (1-2) 75-96 